\title{
Admission to dedicated pediatric cardiac intensive care units is associated with decreased resource use in neonatal cardiac surgery
}

\author{
Joyce T. Johnson, MD, MS, ${ }^{a}$ Jacob F. Wilkes, BS, ${ }^{\mathrm{b}}$ Shaji C. Menon, MD, ${ }^{\mathrm{c}}$ Lloyd Y. Tani, MD, ${ }^{c}$ \\ Hsin-yi Weng, MS, ${ }^{d}$ Bradley S. Marino, MD, MPP, MSCE, ${ }^{a}$ and Nelangi M. Pinto, MD, MS
}

\section{ABSTRACT}

Objective: Neonates undergoing congenital heart surgery require highly specialized, resource-intensive care. Location of care and degree of specialization can vary between and within institutions. Using a multi-institutional cohort, we sought to determine whether location of admission is associated with an increase in health care costs, resource use and mortality.

Methods: We retrospectively analyzed admission for neonates ( $<30$ days) undergoing congenital heart surgery between 2004 and 2013 by using the Pediatric Health Information Systems database (44 children's hospitals). Multivariate generalized estimating equations adjusted for center- and patient-specific risk factors and stratified by age at admission were performed to examine the association of admission intensive care unit (ICU) with total hospital costs, mortality, and length of stay.

Results: Of 19,984 neonates (60\% male) identified, 39\% were initially admitted to a cardiac ICU (CICU), $48 \%$ to a neonatal ICU (NICU), and $13 \%$ to a pediatric ICU. In adjusted models, admission to a CICU versus NICU was associated with a $\$ 20,440$ reduction in total hospital cost for infants aged 2 to 7 days at admission $(P=.007)$ and a $\$ 23,700$ reduction in total cost for infants aged 8 to 14 days at admission $(P=.01)$. Initial admission to a CICU or pediatric ICU versus NICU at $<15$ days of age was associated with shorter hospital and ICU length of stay and fewer days of mechanical ventilation. There was no difference in adjusted mortality by admission location.

Conclusions: Admission to an ICU specializing in cardiac care is associated with significantly decreased hospital costs and more efficient resource use for neonates requiring cardiac surgery. (J Thorac Cardiovasc Surg 2018;155:2606-14)

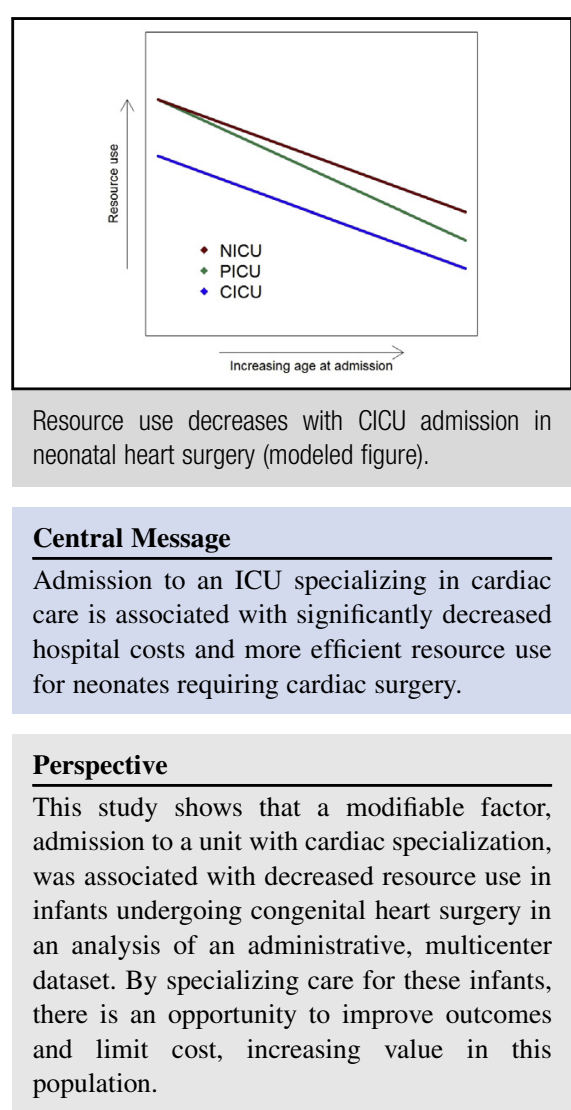

See Editorial Commentary page 2615.

See Editorial page 2604.
Congenital heart defects have the greatest resource use of all birth defects. ${ }^{1}$ Perioperative care for neonatal congenital heart surgery is especially resource intensive, as it requires highly specialized teams with specific knowledge and skill sets. For this reason, much investigation is directed at

From the ${ }^{\mathrm{a}}$ Division of Pediatric Cardiology, Department of Pediatrics, Ann \& Robert H. Lurie Children's Hospital of Chicago, Chicago, Ill; ' Intermountain Healthcare, Pediatric Clinical Program, Salt Lake City, Utah; 'Division of Pediatric Cardiology, Department of Pediatrics, University of Utah at Primary Children's Hospital, Salt Lake City, Utah; and dStudy Design and Biostatistics Center, University of Utah, School of Medicine, Salt Lake City, Utah.

This investigation was supported by the University of Utah Study Design and Biostatistics Center (Salt Lake City, Utah), with funding in part from the National Center for Research Resources and the National Center for Advancing optimizing care delivery to provide the greatest value care. $^{2-5}$

Location of perioperative care of infants with congenital heart disease (CHD) varies both between and within institutions for many reasons, including center surgical volume,

Translational Sciences, National Institutes of Health, through Grant 8UL1TR000105 (formerly UL1RR025764).

Received for publication Aug 28, 2017; revisions received Nov 26, 2017; accepted for publication Jan 17, 2018; available ahead of print March 14, 2018.

Address for reprints: Joyce T. Johnson, MD, MS, 225 E Chicago Ave, Box 21,

Chicago, IL 60611 (E-mail: jtjohnson@luriechildrens.org). $0022-5223 / \$ 36.00$

Copyright (C) 2018 by The American Association for Thoracic Surgery https://doi.org/10.1016/j.jtcvs.2018.01.100 


\section{Abbreviations and Acronyms \\ CHD = congenital heart disease \\ CICU = cardiac intensive care unit \\ ICD-9 = International Classification of \\ Diseases, Ninth Revision \\ ICU = intensive care unit \\ IQR $=$ interquartile range \\ LOS = length of stay \\ NICU = neonatal intensive care unit \\ PHIS $=$ Pediatric Health Information Systems \\ PICU = pediatric intensive care unit \\ RACHS-1 = risk adjustment for congenital heart surgery}

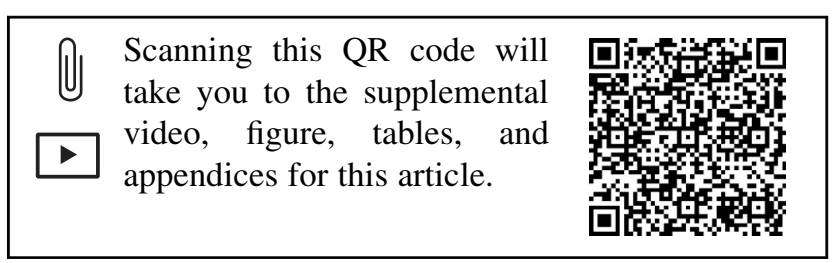

institutional and personnel resources, institutional preferences, financial considerations, historical precedent, and/or political factors. Studies evaluating the impact of intensive care unit (ICU) specialization on outcomes, specifically mortality, in pediatric heart surgery have had conflicting results. One multi-institutional study suggested decreased mortality for neonates cared for in a dedicated cardiac intensive care unit (CICU), whereas another found no association in older children undergoing cardiac surgery. ${ }^{6,7}$ We recently published our institutional findings that admission to a dedicated CICU was associated with lower hospital costs and resource use compared with admission to a neonatal intensive care unit (NICU) for prenatally diagnosed neonates requiring congenital heart surgery. ${ }^{8}$

The influence of location of care, a proxy for care specialization, on costs and outcomes in congenital surgery across pediatric hospitals with differing structures and surgical volumes requires further study, particularly to determine whether our center findings are generalizable across institutions with differing models of care. The purposes of this study were (1) to assess the association between admission location and hospital costs and resource use; and (2) to explore a possible association of admission location with mortality in neonates undergoing congenital heart surgery across multiple institutions.

\section{PATIENTS AND METHODS}

\section{Study Design}

This study analyzed retrospective observational cohort data from the Pediatric Hospital Information Systems (PHIS) database. PHIS is an administrative dataset that contains information regarding inpatient admission from 44 pediatric hospitals, representing 17 metropolitan areas. When compared with clinical registry data, the PHIS database captures approximately $86 \%$ of cardiac surgery cases that fall into a risk adjustment for congenital heart surgery (RACHS-1) category. ${ }^{9,10}$ Data available include demographics, dates of admission and discharge, vital status at discharge, and billing data for medications, laboratory tests, surgical procedures, imaging procedures, clinical services, and supplies. Data are deidentified at the time of data collection and reviewed for reliability and validity before inclusion. A collaboration between the Children's Hospital Association and participating hospitals ensures data quality. Given the nature of this data, institutional board review was not required. ${ }^{11}$

\section{Study Population}

Neonates undergoing cardiac surgery at age $<30$ days with a RACHS- 1 score of 2 to $6^{10}$ at a PHIS hospital from January 2004 through December 2013 were included. Cardiac surgeries in infants $<30$ days by definition must be classified greater than RACHS- 1 score 1 . Infants initially admitted to any unit other than an ICU were excluded (5\%). Patients were identified for inclusion in the study population by the use of cardiac surgery procedure codes.

\section{Data Collection}

Study variables were gathered from International Classification of Diseases, Ninth Revision (ICD-9) and billing codes. Data collected included demographic information, patient characteristics, risk factors, center data, and charge/cost data. Demographic data included sex, race, and payor. Patient characteristics included admission unit, admission age, admission year, use of prostaglandins, and RACHS-1 score. Risk factors including prematurity, low birth weight, the presence of genetic or major noncardiac abnormality, and heterotaxy syndrome were collected by using the prespecified ICD-9 codes listed in Appendix E1. Complications, including chylothorax, cardiac arrest, use of extracorporeal membrane oxygenation, medical complications, surgical complications, and infections were collected using a combination of flags defined in the PHIS system and ICD-9 codes. ${ }^{12}$ A complete list of the findings flagged as medical complications, surgical complications, or infections can be found in Appendix E1. ${ }^{12}$

Center-level variables included hospital census region and volume of cardiac cases per year. Volume of cardiac cases was calculated using the total number of neonatal cases reported per hospital divided by the number of years reported. Hospital volume was divided into tertiles for the purposes of analysis. Total and category-specific charge data were also collected. Data from hospitals missing charge-to-cost ratios $(3 / 44,7 \%)$ were excluded from the cost analysis.

\section{Exposure}

The primary exposure of interest was the initial admission location. Admission location was classified as CICU, NICU, or pediatric intensive care unit (PICU) based on the charges documented on the first day of admission at the pediatric hospital. Infants with CICU charges on the initial day of admission were categorized as CICU. On detailed examination, some institutions with known CICUs used charge codes for PICU. Therefore, those coded as PICU in PHIS likely represent a mix of institutions with multidisciplinary PICUs and institutions with dedicated CICUs that charge as "PICU." For this reason, and since "PICU" designated admissions represented only $13 \%$ of the cohort, we primarily examined the comparison of the PHIS classified CICU to NICU admissions. We did perform a secondary analysis comparing PHIS classified PICU to NICU admissions separately. Although specialization of care actually provided in each unit cannot be known in an administrative dataset, we would generally expect that the presence of cardiac intensive care-trained physicians, pediatric cardiology, pediatric cardiothoracic surgical, and specially trained nurses and their influence on management 
would be greatest in a CICU, least in NICUs, and somewhere in between in PICUs, given their heterogeneity in this dataset. ${ }^{13,14}$

We know some patients initially admitted to one ICU will transfer preoperatively or postoperatively to another type of ICU. However, the exposure of initial admission location and resulting care decisions will influence downstream outcomes and resource use. For example, a cardiac arrest or infection in the initial unit would likely influence health status and resource use thereafter, even after transfer. Thus, to reduce bias, location of initial admission was treated similar to an "intention-to-treat" variable in a randomized control trial by assigning patients to their initial admission ICU exposure cohort. Nonetheless, for transparency and completeness, we also summarized transfers for the cohort throughout the hospitalization.

\section{Outcomes}

The primary outcome analyzed was total hospital cost. Total hospital cost was calculated by multiplying total hospital charges per patient by hospital-specific charge-to-cost ratios. Costs were also adjusted for geographic area and for inflation to 2013 dollars using the Health Care Finance Administration wage/price index and the All Urban Consumers Consumer Price Index. ${ }^{15,16}$ Charge data from subcategories including imaging, clinical, laboratory tests, pharmacy, supply, and other charges were collected. These charges were not converted to costs because category specific charge to cost ratios are not available by hospital. Secondary outcomes of interest included preoperative length of stay (LOS), total hospital LOS, ICU LOS, days of mechanical ventilation, and mortality before discharge.

\section{Covariates}

Covariates for the adjusted analysis were chosen a priori based on hypothesized clinical significance and potential for confounding and interaction. Covariates included in the multivariable analyses included prematurity, low birth weight, sex, race, prostaglandin use, genetic or major noncardiac abnormality, the presence of heterotaxy syndrome, RACHS-1 score, center volume (tertiles), payor, and admission year.

\section{Statistical Analysis}

Patient, center, and hospital cost data were summarized. Continuous data were expressed as means with standard deviations or medians with interquartile ranges (IQRs) as appropriate. Categorical data were tabulated. Univariate $P$ values were calculated with the $\chi^{2}$ tests, Kruskal-Wallis test, univariate linear, and logistic regression where appropriate. Generalized estimated equations were used to fit a series of multivariable linear regression models to relate the primary and secondary outcomes to the initial admission location after adjusting for patient-level covariates. We specified a gamma-distributed outcome model with a log link function for each of these outcome variables. A working exchangeable correlation model was used to account for clustering by hospital. The point estimate of the effect attributable to the exposure compared with the NICU as referent was determined. The secondary outcome of mortality before discharge was analyzed with generalized estimating equations under a multivariable logistic regression model for a binary outcome with a logit link, again using a working exchangeable correlation model to account for clustering by hospital.

To better understand the interaction of age at admission and admission location on outcome, each of the aforementioned analyses were repeated within each of the following age categories: $\leq 1$ day, 2 to 7 days, 8 to 14 days, and $>15$ days at admission. The group admitted at $\leq 1$ day of age was believed to represent a mix of infants diagnosed prenatally or immediately after birth with CHD, as well as a group of infants more likely to be admitted to a NICU for reasons that may have not been fully captured by our covariates, such as uncoded prematurity or growth restriction. We also evaluated the interaction between center volume and admission location. The association of charges by discrete category and admission location were evaluated with a generalized estimating equation. All models were adjusted for predetermined covariates as discussed previously.

Three additional sensitivity analyses were performed for the primary outcome of total hospital cost. To examine the robustness of our results and the impact of inherent differences in the population that might impact choice of initial admission unit, first, a propensity score analysis with one-to-one matching for initial admission to the CICU versus the NICU was performed. Second, to specifically exclude the impact of prematurity, one of the main factors that would affect an admission unit, a sensitivity analysis of total cost excluding patients who categorized as premature was performed. Lastly, although an overall estimate of resource use requires inclusion of all patients regardless of outcome, we also performed a sensitivity analysis of total cost excluding patients with in-hospital mortality, given the variable effect of mortality on cost.

Two-sided $P$ values $<.05$ were considered significant. Data analyses were performed via SAS 9.4 (SAS Institute Inc, Cary, NC) and Stata 12.1 (StataCorp. 2011. Stata Statistical Software: Release 12.1; StataCorp LP, College Station, Tex).

\section{RESULTS}

A total of 19,984 patients met study criteria; $39 \%$ (7830) were initially admitted to a CICU, 48\% (9493) to a NICU, and $13 \%$ (2661) to a PICU (Figure E1). Descriptive data for the cohort are listed in Table 1. Patients admitted to the NICU were more likely to be premature, have low birth weight, and/or have genetic or other major noncardiac abnormalities. Twenty percent of patients were transferred from their initial admission ICU to another before surgery, with a larger percentage of primarily non-CICU patients moving after surgery (Table 2). Patients admitted to the NICU spent a median of $55 \%$ of their total ICU time in the NICU, compared with a median of $0 \%$ NICU time in both CICU admits $(P<.001)$ and PICU admits $(P<.001)$. On univariate analysis, complications also varied between units, with a significantly greater percentage of infectious complications and chylothorax found in NICU admissions compared with the CICU admissions (Table 1).

\section{Total Hospital Cost}

Cost data were available for 18,065 (90\%) patients. Those with cost data were more likely to have government insurance, to be admitted at a later era, to be from the South, admitted to a lower-volume center, and admitted to a NICU. With regard to resource use, patients with cost data available had slightly longer hospital and ICU LOS and days of mechanical ventilation compared with those without (Table E1). Median total hospital cost for the surgical hospitalization was $\$ 110,240$ (IQR $\$ 68,790-187,920)$. In adjusted models stratified by age at admission, initial admission at $\leq 1$ day of age to a CICU compared with a NICU was associated with no difference in cost. Initial admission to the CICU was associated with lower total costs compared with the NICU at 2 to 7 days of age ( $\$ 20,440$ reduction) and 8 to 14 days of age (\$23,700 reduction) with no significant 
TABLE 1. Univariate demographic, covariate variables, and outcome measures by admission location

\begin{tabular}{|c|c|c|c|c|}
\hline Variable/outcome & $\begin{array}{c}\text { NICU } \\
\mathbf{N}=\mathbf{9 4 9 3 ( 4 8 \% )}\end{array}$ & $\begin{array}{c}\text { CICU } \\
\mathbf{N}=\mathbf{7 8 3 0}(39 \%)\end{array}$ & $\begin{array}{c}\text { PICU } \\
\mathbf{N}=\mathbf{2 6 6 1}(13 \%)\end{array}$ & $P$ value \\
\hline \multicolumn{5}{|l|}{ Demographics } \\
\hline Male sex, n (\%) & $5669(60)$ & $4675(60)$ & $1593(60)$ & .9 \\
\hline Race, n (\%) & & & & $<.001$ \\
\hline Non-Hispanic black & $859(9)$ & $870(11)$ & $201(8)$ & \\
\hline Hispanic & $1451(15)$ & $1038(13)$ & $556(21)$ & \\
\hline Non-Hispanic white & $4772(50)$ & $3964(51)$ & $1387(52)$ & \\
\hline Asian & $134(1)$ & $65(1)$ & $24(1)$ & \\
\hline Missing or other & $2277(24)$ & $1893(24)$ & 493 (19) & \\
\hline Payor, n (\%) & & & & $<.001$ \\
\hline Private & 3734 (39) & $2816(36)$ & 975 (37) & \\
\hline Government & $4595(48)$ & $3532(45)$ & $1423(53)$ & \\
\hline Other & $1164(12)$ & $1482(19)$ & $263(10)$ & \\
\hline \multicolumn{5}{|l|}{ Patient characteristics } \\
\hline Age at admission, $\mathrm{d}$, mean $\pm \mathrm{SD}$ & $1.9 \pm 3.9$ & $3.2 \pm 5.5$ & $5.9 \pm 7.59$ & $<.001$ \\
\hline Age at admission, d, median (IQR) & $0(0,2)$ & $0(0,3)$ & $0(0,9)$ & $<.001$ \\
\hline Age at admission, $\mathrm{n}(\%)^{*}$ & & & & $<.001$ \\
\hline $0-1 \mathrm{~d}$ & $6996(74)$ & $4858(62)$ & $1284(48)$ & \\
\hline $2-7 d$ & $1706(18)$ & $1778(23)$ & $543(20)$ & \\
\hline $8-14 \mathrm{~d}$ & $556(6)$ & $687(9)$ & $412(15)$ & \\
\hline $15+d$ & $235(2)$ & $506(6)$ & $422(16)$ & \\
\hline Admission year, $\mathrm{n}(\%)$ & & & & $<.001$ \\
\hline 2003 & $85(1)$ & $43(1)$ & $12(0.5)$ & \\
\hline 2004 & $858(9)$ & $665(8)$ & $234(9)$ & \\
\hline 2005 & $934(10)$ & $736(9)$ & $295(11)$ & \\
\hline 2006 & $1022(11)$ & $891(11)$ & $305(11)$ & \\
\hline 2007 & $1097(12)$ & $830(11)$ & $283(11)$ & \\
\hline 2008 & $1176(12)$ & 795 (10) & $211(8)$ & \\
\hline 2009 & $1037(11)$ & $658(8)$ & $213(8)$ & \\
\hline 2010 & $967(10)$ & $677(9)$ & $192(7)$ & \\
\hline 2011 & $875(9)$ & $815(10)$ & $318(12)$ & \\
\hline 2012 & $756(8)$ & $861(11)$ & $301(11)$ & \\
\hline 2013 & $686(7)$ & 859 (11) & $297(11)$ & \\
\hline Prostaglandin use, $\mathrm{n}(\%)$ & $7428(78)$ & $6146(78)$ & $2076(78)$ & .9 \\
\hline RACHS-1 score, n (\%) & & & & $<.001$ \\
\hline 2 & $1979(21)$ & $1566(20)$ & $736(28)$ & \\
\hline 3 & $3505(37)$ & $2920(37)$ & $880(33)$ & \\
\hline 4 & $2620(28)$ & $1958(25)$ & $696(26)$ & \\
\hline 5 & $55(1)$ & $44(1)$ & $21(1)$ & \\
\hline 6 & $1334(14)$ & $1342(17)$ & $328(12)$ & \\
\hline \multicolumn{5}{|l|}{ Risk factors } \\
\hline Prematurity, n (\%) & $1428(15)$ & $720(9)$ & $195(7)$ & $<.001$ \\
\hline Low birth weight, $\mathrm{n}(\%) \dagger$ & $1196(12)$ & $567(7)$ & $149(6)$ & $<.001$ \\
\hline $\begin{array}{l}\text { Other genetic or major noncardiac } \\
\text { defect, } \mathrm{n}(\%)\end{array}$ & 1409 (15) & $884(11)$ & $263(10)$ & $<.001$ \\
\hline Heterotaxy syndrome, n (\%) & $601(6)$ & $358(5)$ & $117(4)$ & $<.001$ \\
\hline \multicolumn{5}{|l|}{ Center data } \\
\hline Census region, $\mathrm{n}(\%)$ & & & & $<.001$ \\
\hline Midwest & $2866(30)$ & $886(11)$ & 784 (29) & \\
\hline Northeast & $1436(15)$ & $1912(24)$ & $237(9)$ & \\
\hline South & $2713(29)$ & $2853(36)$ & $1058(40)$ & \\
\hline West & $2478(26)$ & $2179(28)$ & $582(22)$ & \\
\hline
\end{tabular}


TABLE 1. Continued

\begin{tabular}{|c|c|c|c|c|}
\hline Variable/outcome & $\begin{aligned} & \text { NICU } \\
N= & 9493(48 \%)\end{aligned}$ & $\begin{array}{c}\text { CICU } \\
\mathbf{N}=\mathbf{7 8 3 0}(39 \%)\end{array}$ & $\begin{array}{c}\text { PICU } \\
\mathbf{N}=2661(13 \%)\end{array}$ & $P$ value \\
\hline Center volume, n (\%) & & & & $<.001$ \\
\hline Lowest tertile, $<50$ cases/y & $3146(33)$ & 2104 (27) & $760(29)$ & \\
\hline Middle tertile, $50-75$ cases/y & $3095(33)$ & $4958(63)$ & $372(14)$ & \\
\hline Highest tertile, $>75$ cases/y & $3252(34)$ & $768(10)$ & $1529(57)$ & \\
\hline \multicolumn{5}{|l|}{ Complications/infections, n (\%) } \\
\hline Chylothorax & $558(6)$ & $290(4)$ & $123(5)$ & $<.001$ \\
\hline Medical complications & $165(2)$ & $108(1)$ & $24(1)$ & .004 \\
\hline Surgical complications & $4720(50)$ & $3811(49)$ & $1213(46)$ & .001 \\
\hline Infectious complications & 3678 (39) & $2186(28)$ & $787(30)$ & $<.001$ \\
\hline ECMO & $630(7)$ & $556(7)$ & $210(8)$ & .07 \\
\hline \multicolumn{5}{|l|}{ Outcomes } \\
\hline Total hospital cost, median (IQR) & $\$ 106,470(\$ 57,830, \$ 185,500)$ & $\$ 100,202(\$ 63,890,169,410)$ & $\$ 118,480(\$ 75,110, \$ 201,410)$ & $<.001$ \\
\hline Total hospital LOS, median (IQR) & $24(15,42)$ & $17(11,30)$ & $18(10,33)$ & $<.001$ \\
\hline ICU LOS, median (IQR) & $18(11,34)$ & $11(6,20)$ & $13(7,23)$ & $<.001$ \\
\hline $\begin{array}{l}\text { Days of mechanical ventilation, } \\
\text { median (IQR) }\end{array}$ & $6(3,13)$ & $6(3,10)$ & $6(3,11)$ & $<.001$ \\
\hline Preoperative LOS, median (IQR) & $5(2,8)$ & $3(1,5)$ & $3(1,6)$ & $<.001$ \\
\hline Postoperative LOS, median (IQR) & $19(10,35)$ & $14(8,26)$ & $14(7,28)$ & $<.001$ \\
\hline Mortality, n (\%) & $830(9)$ & $600(8)$ & $224(8)$ & .04 \\
\hline
\end{tabular}

NICU, Neonatal intensive care unit; $C I C U$, cardiac intensive care unit; $P I C U$, pediatric intensive care unit; SD, standard deviation; IQR, interquartile range; RACHS-1, risk adjustment for congenital heart surgery; ECMO, extracorporeal membrane oxygenation; $L O S$, length of stay; ICU, intensive care unit. *Age of admission not available for 1 CICU subject. †Definition available in Appendix E1. $\ddagger$ Total cost available for 18,065 (90\%) of total cohort.

difference at $>15$ days of age (Figure 1). The full multivariate model is available in Table E2. The propensity score model confirmed the results of the primary model (Table E3). When infants who were premature were excluded, the results were similar for infants admitted at age 2 to 7 days with change in the same direction for those 8 to 14 days (Table E4).

When patients who died before discharge were excluded from the analysis, the findings were similar with the exception of the following: there was no longer a significant difference in cost between admission to the CICU and NICU at 2 to 7 days of age (Table E5).

We found a significant interaction between admission location and center volume with respect to total hospital cost (Table 3). When stratified by age at admission and center volume, admission to the CICU was associated with a lower total hospital cost for all ages at admission compared with the NICU for the greatest center volume tertile. At the lowest volume tertile, there was no significant difference in costs between the CICU and NICU except for an isolated finding of greater total hospital costs with admission to the CICU for those $\leq 1$ day of age at admission.

Charges by category were evaluated to assess the source of cost differences. Adjusted differences in charges by category and admission unit and age are shown in Figure 2. Room charges had the largest magnitude difference, with lower charges for those admitted to the CICU compared with the NICU. Other statistically significant differences were found in pharmacy, imaging, and clinical categories (Figure 2).

\section{Secondary Outcome: Measures of Hospital Resource Use}

Median hospital LOS for all 19,984 patients was 21 days (IQR 13-36) with a median ICU stay of 14 days (IQR 3-12). Median days of mechanical ventilation for the cohort were 6 days (IQR 3-12), and median preoperative LOS was 4 days (IQR 1-6). In univariate analysis, those admitted to the CICU had shorter postoperative LOS than those admitted to the NICU. In adjusted models, admission to

TABLE 2. Movement of patients from initial ICU before and after cardiac surgery

\begin{tabular}{lccc}
\hline $\begin{array}{c}\text { Initial ICU } \\
\text { of admission }\end{array}$ & $\begin{array}{c}\text { Transfer to another } \\
\text { ICU in first } \mathbf{4 8} \mathbf{~ h}, \mathbf{n}(\%)\end{array}$ & $\begin{array}{c}\text { Transfer to another ICU } \\
\text { any time before surgery, } \mathbf{n}(\%)\end{array}$ & $\begin{array}{c}\text { Transfer to another ICU } \\
\text { after surgery, } \mathbf{n}(\%)\end{array}$ \\
\hline NICU & $949(10)$ & $1385(15)$ & $7464(79)$ \\
CICU & $57(1)$ & $124(2)$ & $616(8)$ \\
PICU & $74(3)$ & $93(3)$ & $543(19)$ \\
\hline
\end{tabular}

$I C U$, Intensive care unit; $N I C U$, neonatal intensive care unit; $C I C U$, cardiac intensive care unit; $P I C U$, pediatric intensive care unit. 


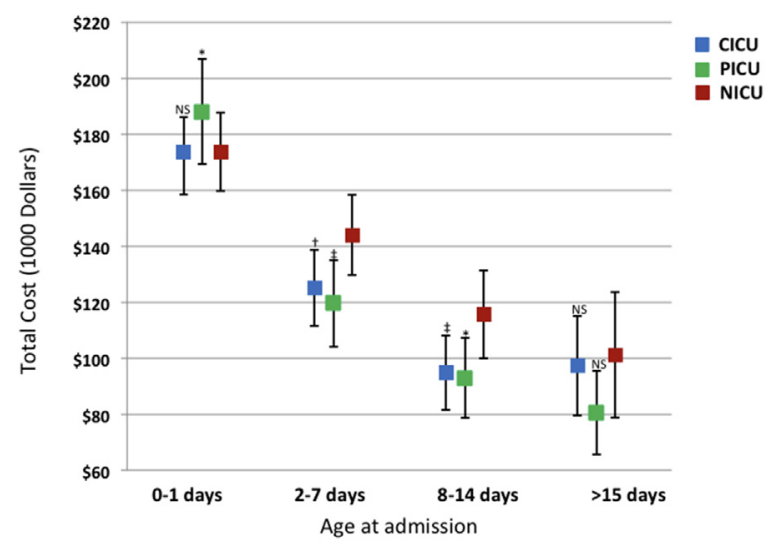

FIGURE 1. Adjusted estimated mean of total hospital cost by unit of admission stratified by age at admission. Blue indicates CICU; green, PICU; and red, NICU admission. ${ }^{*} P<.05, \dagger P<.01$, and $\ddagger P \leq .001$ for comparison with NICU as referent. $C I C U$, Cardiac intensive care unit; $P I C U$, pediatric intensive care unit; $N I C U$, neonatal intensive care unit; $N S$, not significant.

the CICU was associated with shorter hospital LOS and ICU LOS compared with the NICU in all age groups (Table 4). In addition, admission to the CICU was associated with a shorter preoperative LOS than admission to the NICU in the 3 youngest age groups. Those admitted to the CICU had fewer days of mechanical ventilation at all age groups except those admitted at $>15$ days of age.

\section{Secondary Outcome: Hospital Mortality}

Overall hospital mortality for the cohort was 1654/19,984 $(8.3 \%)$. In adjusted models stratified by age, there was no difference in hospital mortality between admission to the $\mathrm{CICU}$ or NICU at any age ( $P$ range, .4 to $>.9$ ).

\section{PICU Analyses}

When the PICU group was compared with the NICU for the primary and secondary outcomes, findings were similar to the CICU versus NICU results described previously. Initial admission to the PICU was associated with lower total costs compared with the NICU at 2 to 7 days of age (\$26,430 reduction) and 8 to 14 days of age $(\$ 25,910$ reduction) with no significant difference at $>15$ days of age (Figure 1). In adjusted models, admission to the PICU was associated with shorter hospital LOS and ICU LOS compared with the NICU in all age groups except those $<1$ day of age at admission (Table 4). Similar to CICU admission, admission to the PICU was associated with a shorter preoperative LOS than admission to the NICU in the 3 youngest age groups. Admission to the PICU was associated with a greater mortality than admission to the NICU in those admitted $\leq 1$ day of age (adjusted odds ratio $1.4,95 \%$ confidence interval, 1.04-1.82) with no significant difference in mortality when compared to the NICU at the other age groups.

\section{DISCUSSION}

In a multicenter analysis of pediatric hospitals across the nation, admission to an ICU specialized in delivering cardiac care is associated with significantly decreased total hospital costs and more efficient resource use for neonates undergoing cardiac surgery. These findings remained significant even after we adjusted for hospital surgical volume as a potential confounder, because high-volume centers are more likely to have specialized CICUs. Adjusted analysis revealed no significant difference in mortality (Video 1).

This multicenter study builds on our previous single-center findings. In the single-center study, we found that in term, prenatally diagnosed infants, CICU admission was associated with shorter hospital and ICU LOS and fewer days of mechanical ventilation but no difference in total cost when compared with the NICU. ${ }^{8}$ In this multicenter analysis with larger sample size, we found a decreased total cost between CICU and NICU admissions. When the effect size is compared with the median total cost for our population, admission to the CICU was associated with a savings of approximately $18 \%$. This represents a significant opportunity for streamlining resource use in this resource-heavy population. ${ }^{1}$ Although determining the specific drivers of these cost differences is challenging and beyond the scope of this analysis, differences in LOS as reflected in differences in room charges likely contribute. We also saw differences in other clinical and pharmacy charges. Furthermore, other factors, such as variation seen in the complication rates between units, may contribute as well.

TABLE 3. Adjusted assessment of the interaction between center volume, age of admission, and admission location on total cost, NICU referent

\begin{tabular}{|c|c|c|c|c|c|c|c|}
\hline & & \multicolumn{2}{|c|}{$\begin{array}{c}\text { Lowest center volume tertile } \\
<\mathbf{5 0} \text { cases/year }\end{array}$} & \multicolumn{2}{|c|}{$\begin{array}{c}\text { Middle center volume tertile } \\
50-75 \text { cases/year }\end{array}$} & \multicolumn{2}{|c|}{$\begin{array}{l}\text { Highest center volume tertile } \\
\quad>75 \text { cases/year }\end{array}$} \\
\hline \multicolumn{2}{|c|}{ Age at admission } & Adjusted difference & $P$ value & Adjusted difference & $P$ value & Adjusted difference & $P$ value \\
\hline $0-1 \mathrm{~d}$ & $\mathrm{CICU}$ & $\$ 87,790$ & $<.001$ & $-\$ 5720$ & .6 & $-\$ 29,070$ & $<.001$ \\
\hline $2-7 d$ & $\mathrm{CICU}$ & $\$ 40,470$ & .2 & $-\$ 19,140$ & .2 & $-\$ 28,330$ & $<.001$ \\
\hline $8-14 \mathrm{~d}$ & $\mathrm{CICU}$ & $\$ 7180$ & .8 & $-\$ 37,470$ & .03 & $-\$ 23,480$ & .02 \\
\hline$>15 \mathrm{~d}$ & $\mathrm{CICU}$ & $-\$ 1050$ & $>.9$ & $\$ 17,000$ & .4 & $-\$ 32,310$ & .008 \\
\hline
\end{tabular}

CICU, Cardiac intensive care unit. 


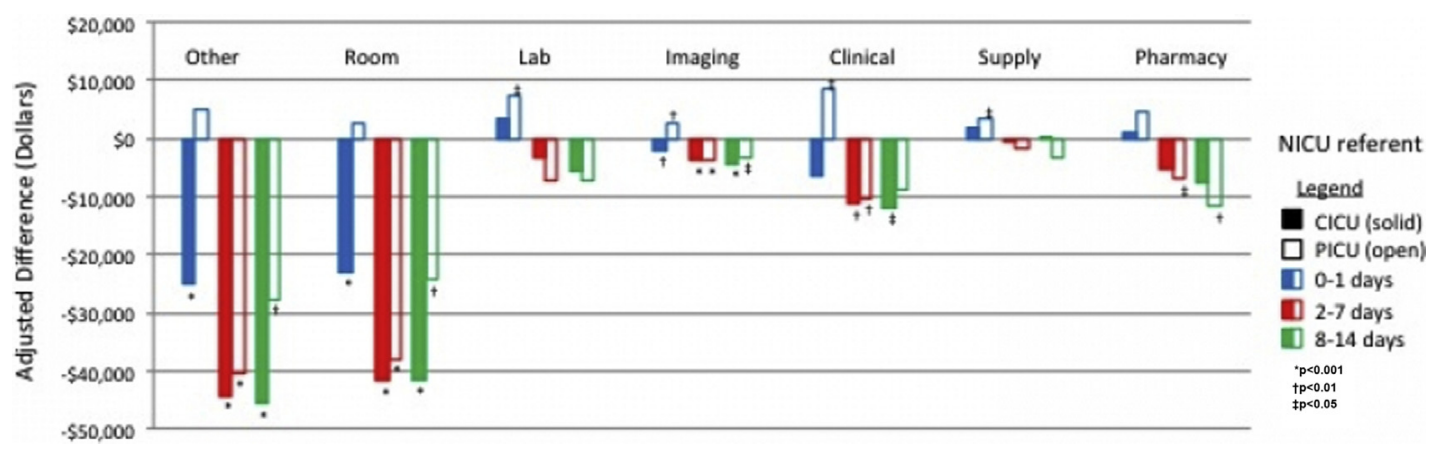

FIGURE 2. Adjusted comparison of difference in charge by category and admission location. For each category, data for CICU and PICU relative to NICU (referent) are displayed. Solid bars, CICU; open bars, PICU. Blue indicates 0 to 1 day of age at admission; red indicates 2 to 7 days of age at admission; and green indicates 8 to 14 days of age at admission. CICU, Cardiac intensive care unit; PICU, pediatric intensive care unit; NICU, neonatal intensive care unit.

Interestingly, our current findings contrast those of Gupta and colleagues, ${ }^{6}$ which suggested that total charges are greater in patients cared for in a CICU versus NICU. They also found a significant difference in mortality favoring the CICU whereas we did not. The difference in these findings may the result of their inclusion of only propensity-matched pairs of patients who did not transfer from one unit to another preoperatively, limiting their analysis to $\sim 12 \%$ of the population of neonates undergoing cardiac surgeries at PHIS hospitals. Because transfers may have been influenced by changes in the patients' medical conditions after their initial ICU admission, this restriction may have introduced selection biases that affected their results.

Of note, in the paper by Gupta and colleagues, $20 \%$ of patients transferred ICUs before surgery, similar to our findings. However, these patients were excluded in the analysis by Gupta and colleagues. Furthermore, the inclusion of only 1:1 matched patients excluded $>85 \%$ of the neonatal CHD surgery population and significantly limits the ability to interpret these findings and apply the findings to the typical clinical setting.

In our analysis, we included a larger selection of the PHIS database hospitals (44/48) and patients $(95 \%$ of those undergoing congenital heart surgery), allowing for a more generalizable sample. In addition, in our cohort, patients who were initially admitted to the NICU spent the majority of their ICU time in the NICU and because there were no transfers from another unit into the NICU after admission, these patients represent a group of patients with time in the NICU as their unique exposure.

We describe significant differences in resource use by admission location that we speculate are due to specialization of care. Admission to a CICU was associated with shorter hospital stays and fewer days of mechanical ventilation in the previous studies. ${ }^{6,8}$ Our study further suggests that intensive care specialization may be advantageous by reducing cost and resource use in neonates undergoing congenital heart surgery. Specialization at the hospital level has been shown to decrease costs, ${ }^{17}$ so it is not surprising

TABLE 4. The adjusted effect of admission location on secondary measures of resource use, NICU referent

\begin{tabular}{|c|c|c|c|c|c|c|c|c|c|c|c|c|}
\hline \multirow[b]{2}{*}{$\begin{array}{c}\text { Age at } \\
\text { admission }\end{array}$} & \multicolumn{3}{|c|}{ Total hospital LOS } & \multicolumn{3}{|c|}{ Total ICU LOS } & \multicolumn{3}{|c|}{ Preoperative LOS } & \multicolumn{3}{|c|}{$\begin{array}{c}\text { Days of mechanical } \\
\text { ventilation }\end{array}$} \\
\hline & $\begin{array}{l}\text { Adjusted } \\
\text { difference }\end{array}$ & $95 \%$ CI & $\begin{array}{c}P \\
\text { value }\end{array}$ & $\begin{array}{l}\text { Adjusted } \\
\text { difference }\end{array}$ & $95 \%$ CI & $\begin{array}{c}P \\
\text { value }\end{array}$ & $\begin{array}{l}\text { Adjusted } \\
\text { difference }\end{array}$ & $95 \%$ CI & $\begin{array}{c}P \\
\text { value }\end{array}$ & $\begin{array}{l}\text { Adjusted } \\
\text { difference }\end{array}$ & $95 \% \mathrm{CI}$ & $\begin{array}{c}P \\
\text { value }\end{array}$ \\
\hline \multicolumn{13}{|l|}{$0-1 \mathrm{~d}$} \\
\hline CICU & -5.4 & -7.4 to -3.5 & $<.001$ & -5.4 & -7.2 to -3.6 & $<.001$ & -1.9 & -2.2 to -1.6 & $<.001$ & -2.8 & -4.3 to -1.4 & $<.001$ \\
\hline PICU & 1.0 & -1.6 to 3.6 & .4 & 0.2 & -2.0 to 2.5 & .8 & -1.2 & -1.6 to -1.0 & $<.001$ & 0.7 & -1.2 to 2.5 & .5 \\
\hline \multicolumn{13}{|l|}{$2-7 d$} \\
\hline CICU & -8.1 & -10.9 to -5.7 & $<.001$ & -7.7 & -10.1 to -5.3 & $<.001$ & -2.1 & -2.6 to -1.7 & $<.001$ & -2.5 & -3.9 to -1.1 & .001 \\
\hline $\mathrm{PICU}$ & -6.7 & -9.5 to -3.9 & $<.001$ & -6.8 & -9.4 to -4.3 & $<.001$ & -1.7 & -2.2 to -1.3 & $<.001$ & -2.7 & -4.3 to -1.2 & .001 \\
\hline \multicolumn{13}{|l|}{$8-14 \mathrm{~d}$} \\
\hline CICU & -8.0 & -11.1 to -4.8 & $<.001$ & -9.2 & -12.5 to -6.0 & $<.001$ & -1.6 & -2.1 to -1.1 & $<.001$ & -2.7 & -4.7 to -0.7 & .008 \\
\hline PICU & -6.4 & -9.8 to -3.0 & $<.001$ & -5.5 & -8.8 to -2.2 & .001 & -1.3 & -1.9 to -0.8 & $<.001$ & -1.9 & -4.0 to 0.3 & .1 \\
\hline \multicolumn{13}{|l|}{$>15 \mathrm{~d}$} \\
\hline $\mathrm{CICU}$ & -9.2 & -14.3 to -4.1 & $<.001$ & -6.4 & -11.0 to -1.9 & .006 & -0.5 & -1.0 to 0.0 & .06 & -2.8 & -6.5 to 1.0 & .2 \\
\hline PICU & -8.6 & -13.8 to -3.4 & .001 & -4.9 & -9.5 to -0.3 & .04 & -0.8 & -1.3 to -0.3 & .001 & -2.7 & -6.4 to 1.1 & .2 \\
\hline
\end{tabular}

LOS, Length of stay; $I C U$, intensive care unit; $C I$, confidence interval; $C I C U$, cardiac intensive care unit; $P I C U$, pediatric intensive care unit. 
that unit-specific specialization would streamline resource use. Although the natural question is whether the NICU patient population differed in ways that we could not account for statistically leading to some selection bias (or confounding by indication), is remains notable that our findings remained robust in the propensity-matched analysis and when infants who were premature were excluded.

Finally, the fact that these findings are aligned with our previous single-center work, where the granularity of our data allowed us to adjust for these confounding indications more adequately, add to the likelihood that this difference in cost is not solely related to inherent differences in the patient populations cared for by these different units. In addition, the fact that some cost differences based on admission unit were no longer present when patients who died before discharge were excluded suggests that, in some instances, cost savings may be due to a difference in timing of deaths between units or a difference in resources used in the highly resource intensive period before death.

Since high-volume centers often are those more likely to have specialized CICUs, understanding the interaction between center volume and age at admission is important. The association between center volume and cost in CHD and between greater center volume and improved outcomes has been reported. ${ }^{3,18-20}$ The interaction between hospital volume and admission location may reflect not just the hospital volume but a difference in the specialization of ICU care related to volume. At lower-volume centers, ICU specialization may be systematically different than at greater-volume centers. This may explain the finding of resource savings for CICU admissions within the greatest-volume centers but the lack of similar findings in lower-volume centers. Likely, as our data suggest, in greater-volume centers, ICU specialization contributes to achieving lower cost care and improved outcomes. Alternatively, greater volume may result in superior specialization that cannot be achieved or sustained at a similar level when the volume of CHD patients results in fewer CICU admissions.

It may not be possible, for all centers, however, to support an individual specialized unit. We would speculate that our study supports specialization of care within any unit, not necessarily only initial admission to a CICU. For example, in smaller centers that cannot support a separate CICU, the best answer may be providing cardiac specific training to a subset of NICU nurses and physicians to attempt to approximate the specialization provided in a CICU.

As with any retrospective study, the possibility of uncontrolled confounding exists. Specifically, we do not have information regarding the physician decision-making process with respect to admission unit or any other measures of quality such as accreditation by professional centers. However, we did control for known covariates that increase the likelihood of admission to the NICU that

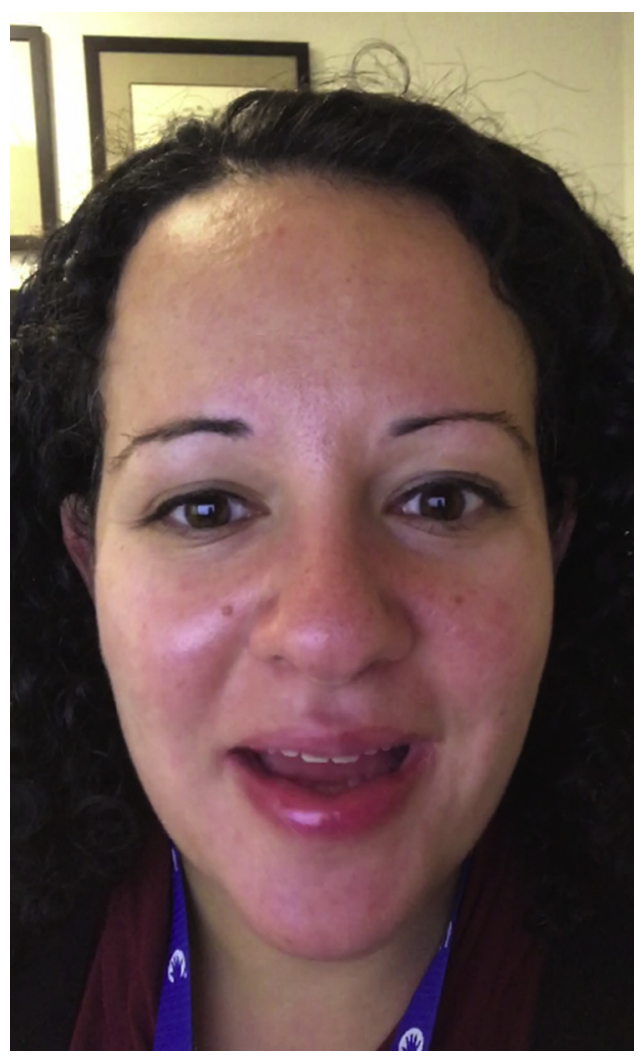

VIDEO 1. Joyce Johnson, MD, MS, describes the key findings and relevance of this multicenter observational study. Video available at: http:// www.jtcvsonline.org/article/S0022-5223(18)30411-2/fulltext.

also impact outcome, and our findings remained robust on multiple sensitivity analyses designed to further address this confounding.

Nonetheless, given our use of administrative data, unmeasured confounders may still exist. As birth weight in grams and gestational age in weeks are frequently missing or inaccurate in PHIS, ICD-9-DM codes were used, as has been done in previous rigorous studies using PHIS. ${ }^{21}$ It is possible that transfer from the initial unit of admission may affect our analysis. Our intent was to determine the effect of initial location of admission on resource, and so patients were analyzed by their initial location of admission as in an intent-to-treat analysis. As transfers from one ICU to another are likely heavily influenced by the patient's condition at the time of transfer, adjusting for those time-dependent factors is difficult and can also introduce bias. In addition, the direction of transfer was almost exclusively from the NICU to another ICU. This supports that initial admission to a NICU has a significant effect on cost and resource use, and that the location of initial admission and preoperative care has a significant impact on the remainder of the hospital course. In addition, isolating cost by each location of care after the initial exposure to an ICU and adjusting for those time-dependent factors is difficult and would introduce 
further bias. Most likely, the lack of significance in the $>15$ days age group is related to a relatively small number of patients in this group.

Another limitation is that as the level of cardiac specialization within the group billed as PICU is not completely known, it likely represents a mix of general PICUs and dedicated CICUs. For that reason, we analyzed this group separately, with only slight differences in the results as noted previously that likely are secondary to their mixed level of specialization. However, it does make makes the comparison of this group to the NICU difficult to interpret. In addition, we do not have any information on care that occurred before admission or transfer to the PHIS hospital. Although PHIS data quality is rigorously confirmed through the Children's Hospital Association and submitting hospitals, the possibility of misclassification exists and cannot be quantified.

\section{CONCLUSIONS}

Our results demonstrate that in a national cohort of pediatric hospitals, initial admission to an ICU specialized in delivering cardiac care results in significantly decreased hospital costs and more efficient resource use for neonates requiring cardiac surgery. Although mortality was not shown to be different, in the current era of capitated payments and efforts to provide value-based care, cost reduction and more efficient resource use is key while optimizing outcome. This study indicates the importance of increased cardiac specialization and sufficient patient volume to maintain specialization within the constraints of physical location in the care of these patients.

\section{Conflict of Interest Statement}

Authors have nothing to disclose with regard to commercial support.

The authors acknowledge the contributions of Dr Tom Greene for his statistical expertise and Dr Lajja Desai for her editorial assistance.

\section{References}

1. Russo CA, Elixhauser A. Hospitalizations for Birth Defects, 2004: Statistical Brief \#24. Healthcare Cost and Utilization Project (HCUP) Statistical Briefs. Rockville, MD: Agency for Healthcare Research and Quality (US); 2006-2007.

2. Pasquali SK, Jacobs JP, Bove EL, Gaynor JW, He X, Gaies MG, et al. Quality-cost relationship in congenital heart surgery. Ann Thorac Surg. 2015; 100:1416-21.

3. Connor JA, Gauvreau K, Jenkins KJ. Factors associated with increased resource utilization for congenital heart disease. Pediatrics. 2005;116:689-95.
4. Smith AH, Gay JC, Patel NR. Trends in resource utilization associated with the inpatient treatment of neonatal congenital heart disease. Congenit Heart Dis. 2014;9:96-105.

5. Chan T, Kim J, Minich LL, Pinto NM, Waitzman NJ. Surgical volume, hospital quality, and hospitalization cost in congenital heart surgery in the united states. Pediatr Cardiol. 2015;36:205-13.

6. Gupta P, Beam BW, Noel TR, Dvorchik I, Yin H, Simsic JM, et al. Impact of preoperative location on outcomes in congenital heart surgery. Ann Thorac Surg. 2014;98:896-903.

7. Burstein DS, Jacobs JP, Li JS, Sheng S, O'Brien SM, Rossi AF, et al. Care models and associated outcomes in congenital heart surgery. Pediatrics. 2011;127: e1482-1489.

8. Johnson JT, Tani LY, Puchalski MD, Bardsley TR, Byrne JL, Minich LL, et al. Admission to a dedicated cardiac intensive care unit is associated with decreased resource use for infants with prenatally diagnosed congenital heart disease. Pediatr Cardiol. 2014;35:1370-8.

9. Pasquali SK, Jacobs JP, Jacobs ML, Gaies MG, Shah SS, Hall M, et al. Measuring hospital performance in congenital heart surgery: administrative versus clinical registry data. Ann Thorac Surg. 2015;99:932-8.

10. Jenkins KJ, Gauvreau K, Newburger JW, Spray TL, Moller JH, Iezzoni LI. Consensus-based method for risk adjustment for surgery for congenital heart disease. J Thorac Cardiovasc Surg. 2002;123:110-8.

11. Children's Hospital Association. Pediatric Health Information Systems (PHIS), 2014. Available at: https://www.childrenshospitals.org/programs-and-services/ data-analytics-and-research/pediatric-analytic-solutions/pediatric-health-infor mation-system. Accessed May 30, 2014.

12. Children's Hospital Association. Flag code lists-FY 2013. Available at: https:// www.childrenshospitals.org/ /media/Files/Groups/PHIS/Reference \%20Resources/ Data $\% 20$ Content/Other $\% 20$ Materials/FlagsInfection $\% 20$ Med $\% 20$ Comp $\% 20$ Surg \%20Comp\%20Current\%20List.pdf. Accessed May 30, 2014.

13. Daenen W, Lacour-Gayet F, Aberg T, Comas JV, Daebritz SH, Di Donato R, et al. Optimal structure of a congenital heart surgery department in Europe: by EACTS Congenital Heart Disease Committee. Eur J Cardiothorac Surg. 2003;24:343-51.

14. Baden HP, Zimmerman JJ, Brilli RJ, Wong H, Wetzel RC, Burns JP, et al. Intensivist-led team approach to critical care of children with heart disease. Pediatrics. 2006;117:1854-6.

15. O'Byrne ML, Gillespie MJ, Shinohara RT, Dori Y, Rome JJ, Glatz AC. Cost comparison of transcatheter and operative pulmonary valve replacement (from the Pediatric Health Information Systems database). Am J Cardiol. 2016;117: 121-6.

16. Bureau of Labor Statistics. All urban consumers consumer price index. Available at: http://www.bls.gov/cpi. Accessed May 30, 2014.

17. Eastaugh SR. Hospital specialization and cost efficiency: benefits of trimming product lines. Hosp Health Serv Adm. 1992;37:223-35.

18. Kansy A, Ebels T, Schreiber C, Tobota Z, Maruszewski B. Association of center volume with outcomes: analysis of verified data of European Association for Cardio-Thoracic Surgery Congenital Database. Ann Thorac Surg. 2014;98: 2159-64.

19. Karamlou T, Jacobs ML, Pasquali S, He X, Hill K, O'Brien S, et al. Surgeon and center volume influence on outcomes after arterial switch operation: analysis of the STS congenital heart surgery database. Ann Thorac Surg. 2014;98:904-11.

20. Pasquali SK, Sun JL, d'Almada P, Jaquiss RD, Lodge AJ, Miller N, et al. Center variation in hospital costs for patients undergoing congenital heart surgery. Circ Cardiovasc Qual Outcomes. 2011;4:306-12.

21. Lillehei CW, Gauvreau K, Jenkins KJ. Risk adjustment for neonatal surgery: a method for comparison of in-hospital mortality. Pediatrics. 2012;130: e568-574.

Key Words: neonatal congenital heart disease, surgical repair, resource use, intensive care unit 


\section{APPENDIX E1}

International Classification of Diseases, Ninth Revision (ICD-9) codes:

Chylothorax: 457.8

Prematurity: for extreme immaturity (765.0), other preterm infants $(765.1)$, or weeks of gestation $<37$ weeks (765.26, 765.28).

Low birth weight was defined as the presence of ICD-9 codes for slow fetal growth and fetal malnutrition (764) and low birth weight status (V21.3).

Genetic or other major noncardiac abnormality was defined as the presence of ICD-9 codes for known and other genetic syndromes and congenital anomalies
$(279.11,279.12,279.13,756.16,758.0-9,759.7-9,259.4$, 737.3, 756.0-7, 553.3).

Heterotaxy syndrome was defined as the presence of ICD-9 codes for congenital anomalies of the spleen (759.0), situs inversus (759.3), or other anomalies of the great veins (747.49).

Surgical, medical, and infection complications flags as defined by Pediatric Health Information Systems can be found through the Children's Hospital Association Web site: https://www.childrenshospitals.org/ /media/Files/ Groups/PHIS/Reference \%20Resources/Data \%20Content/ Other $\% 20$ Materials/Flagsinfection $\% 20$ Med $\% 20$ Comp $\%$ 20Surg \%20Comp \%20Current \%20List.pdf. 


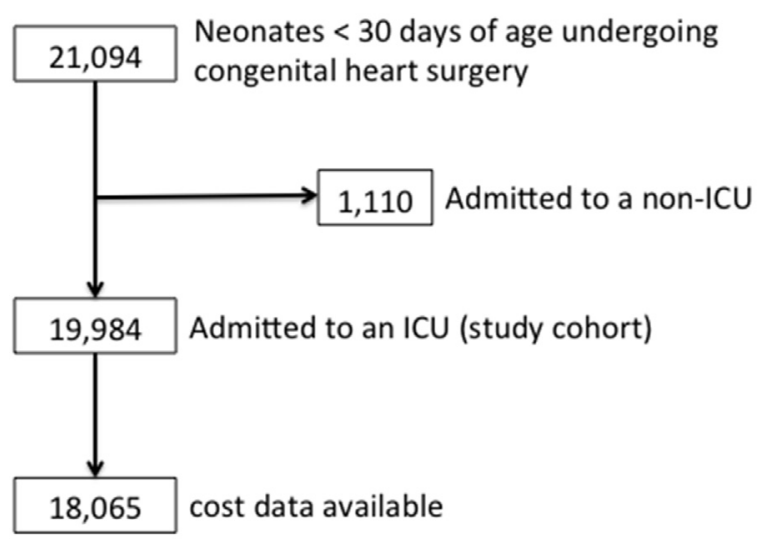

FIGURE E1. Diagram of cohort inclusion. ICU, Intensive care unit. 
TABLE E1. Comparison of those with and without cost data

\begin{tabular}{|c|c|c|c|}
\hline $\begin{array}{c}\text { Covariates and } \\
\text { outcomes }\end{array}$ & $\begin{array}{c}\text { Observations } \\
\text { with } \\
\text { hospital cost } \\
(\mathrm{n}=18,065 \\
90.4 \%)\end{array}$ & $\begin{array}{c}\text { Observations } \\
\text { without } \\
\text { hospital cost } \\
(\mathrm{n}=1919 \\
9.6 \%)\end{array}$ & $\begin{array}{c}P \\
\text { value }\end{array}$ \\
\hline \multicolumn{4}{|l|}{ Patient demographics } \\
\hline Male, n (\%) & $10,808(60)$ & $1129(59)$ & .40 \\
\hline Race, n (\%) & & & $<.0001$ \\
\hline Non-Hispanic white & $9170(51)$ & $953(50)$ & \\
\hline Non-Hispanic black & $1623(9)$ & 307 (16) & \\
\hline Hispanic & 2818 (16) & $227(12)$ & \\
\hline Asian & $210(1)$ & $13(1)$ & \\
\hline Missing/other & $4244(23)$ & $419(22)$ & \\
\hline Payer, n (\%) & & & $<.0001$ \\
\hline Government & 8824 (49) & $726(38)$ & \\
\hline Private & $6628(37)$ & $897(47)$ & \\
\hline Other & $2613(14)$ & $296(15)$ & \\
\hline \multicolumn{4}{|l|}{ Patient characteristics } \\
\hline $\begin{array}{l}\text { Age at admitted, } \mathrm{d}, \\
\text { median (range) }\end{array}$ & $1(0,29)$ & $0(0,29)$ & $<.0001$ \\
\hline Admitted year, n (\%) & & & $<.0001$ \\
\hline 2003 & $107(1)$ & $33(2)$ & \\
\hline 2004 & $1205(7)$ & $552(29)$ & \\
\hline 2005 & $1742(10)$ & $223(12)$ & \\
\hline 2006 & $2048(11)$ & $170(9)$ & \\
\hline 2007 & $2123(12)$ & $87(5)$ & \\
\hline 2008 & 2055 (11) & $127(7)$ & \\
\hline 2009 & $1736(10)$ & $172(9)$ & \\
\hline 2010 & $1694(9)$ & $142(7)$ & \\
\hline 2011 & $1876(10)$ & $132(7)$ & \\
\hline 2012 & $1787(10)$ & $131(7)$ & \\
\hline 2013 & $1692(9)$ & $150(8)$ & \\
\hline Prostaglandin use, $\mathrm{n}(\%)$ & $12,093(67)$ & $1322(69)$ & .08 \\
\hline RACHS-1 score, n (\%) & & & .0001 \\
\hline 2 & $3919(22)$ & $362(19)$ & \\
\hline 3 & $6576(36)$ & $729(38)$ & \\
\hline 4 & $4804(27)$ & $470(24)$ & \\
\hline 5 & $108(1)$ & $12(1)$ & \\
\hline 6 & $2658(15)$ & $346(18)$ & \\
\hline \multicolumn{4}{|l|}{ Risk factors } \\
\hline Premature, $\mathrm{n}(\%)$ & $2148(12)$ & $195(10)$ & .03 \\
\hline Low birth weight, $\mathrm{n}(\%)$ & $1736(10)$ & $176(9)$ & .53 \\
\hline $\begin{array}{l}\text { Other congenital defect, } \\
\mathrm{n}(\%)\end{array}$ & $2329(13)$ & 227 (12) & .18 \\
\hline Heterotaxy, n (\%) & $989(5)$ & $87(5)$ & .08 \\
\hline \multicolumn{4}{|l|}{ Complications/infections } \\
\hline Chylothorax, n (\%) & $915(5)$ & $56(3)$ & $<.0001$ \\
\hline $\begin{array}{l}\text { Medical complication, } \\
\mathrm{n}(\%)\end{array}$ & $266(1)$ & $31(2)$ & .62 \\
\hline $\begin{array}{l}\text { Surgery complication, } \\
\mathrm{n}(\%)\end{array}$ & $8796(49)$ & $948(49)$ & .55 \\
\hline Infection, $\mathrm{n}(\%)$ & $6048(33)$ & $603(31)$ & .07 \\
\hline ECMO, n $(\%)$ & $1258(7)$ & $138(7)$ & .71 \\
\hline
\end{tabular}

TABLE E1. Continued

\begin{tabular}{|c|c|c|c|}
\hline $\begin{array}{c}\text { Covariates and } \\
\text { outcomes }\end{array}$ & $\begin{array}{c}\text { Observations } \\
\text { with } \\
\text { hospital cost } \\
(\mathrm{n}=18,065 \\
90.4 \%)\end{array}$ & $\begin{array}{c}\text { Observations } \\
\text { without } \\
\text { hospital cost } \\
(\mathrm{n}=1919 \\
9.6 \%)\end{array}$ & $\begin{array}{c}P \\
\text { value }\end{array}$ \\
\hline \multicolumn{4}{|l|}{ Center data } \\
\hline Region, n (\%) & & & $<.0001$ \\
\hline West & $5018(28)$ & $221(12)$ & \\
\hline South & $6335(35)$ & $289(15)$ & \\
\hline Northeast & $2238(12)$ & $1347(70)$ & \\
\hline Midwest & $4474(25)$ & $62(3)$ & \\
\hline Central volume, n (\%) & & & $<.0001$ \\
\hline$<50.1$ & $5187(29)$ & 362 (19) & \\
\hline $50.1-74.8$ & $5941(33)$ & $69(4)$ & \\
\hline$\geq 74.8$ & $6937(38)$ & $1488(78)$ & \\
\hline \multicolumn{4}{|l|}{ Outcomes } \\
\hline $\begin{array}{l}\text { Length of stay, d, } \\
\text { median (IQR) }\end{array}$ & $21(13,36)$ & $18(11,36)$ & $<.0001$ \\
\hline $\begin{array}{l}\text { Mechanical ventilation, } \mathrm{d} \text {, } \\
\text { median (IQR) }\end{array}$ & $6(3,12)$ & $4(2,10)$ & $<.0001$ \\
\hline ICU LOS, d, median (IQR) & $15(8,27)$ & $13(7,25)$ & $<.0001$ \\
\hline $\begin{array}{l}\text { Preoperative LOS, } \\
\text { median (IQR) }\end{array}$ & $4(1,7)$ & $3(1,5)$ & $<.0001$ \\
\hline Mortality, n (\%) & $1476(8)$ & $178(9)$ & .09 \\
\hline Admission locations, $\mathrm{n}(\%)$ & & & $<.0001$ \\
\hline $\mathrm{CICU}$ & $6430(36)$ & $1400(73)$ & \\
\hline NICU & $9100(50)$ & $393(20)$ & \\
\hline PICU & 2535 (14) & $126(7)$ & \\
\hline
\end{tabular}

RACHS-1, Risk adjustment for congenital heart surgery; ECMO, extracorporeal membrane oxygenation; $I Q R$, interquartile range; $I C U$, intensive care unit $L O S$, length of stay; $C I C U$, cardiac intensive care unit; $N I C U$, neonatal intensive care unit; $P I C U$, pediatric intensive care unit. 
TABLE E2. Estimated beta coefficients of the covariates in the generalized estimating equation multivariate model for the primary outcome of total hospital cost by age group of admission

\begin{tabular}{|c|c|c|c|c|c|c|c|c|}
\hline Covariate & 0-1 d of age & $P$ value & 2-7 d of age & $P$ value & 8-14 d of age & $P$ value & $>15 \mathrm{~d}$ of age & $P$ value \\
\hline Male sex & 0.04 & .04 & 0.09 & .01 & 0.1 & .02 & 0.2 & .003 \\
\hline Race & & $<.001$ & & .6 & & .7 & & .5 \\
\hline Non-Hispanic black & 0.2 & $<.001$ & 0.08 & .2 & -0.04 & .7 & 0.2 & .1 \\
\hline Hispanic & 0.05 & .2 & 0.006 & .9 & -0.08 & .3 & -0.09 & .5 \\
\hline Non-Hispanic white & Ref & & Ref & & Ref & & Ref & \\
\hline Asian & -0.02 & .9 & 0.09 & 6 & 0.3 & .3 & -0.2 & 6 \\
\hline Missing or other & 0.08 & .003 & -0.03 & .5 & 0.01 & .9 & 0.009 & .9 \\
\hline Payor & & .04 & & .004 & & $<.01$ & & .7 \\
\hline Private & -0.06 & .01 & -0.08 & .06 & -0.2 & .003 & -0.09 & .4 \\
\hline Government & Ref & & Ref & & Ref & & Ref & \\
\hline Other & -0.03 & .03 & -0.2 & .002 & -0.1 & .1 & -0.06 & .6 \\
\hline Admission year & & $<.001$ & & $<.001$ & & $<.001$ & & .07 \\
\hline 2003 & Ref & & Ref & & Ref & & Ref & \\
\hline 2004 & -0.2 & .05 & -0.5 & .08 & -0.7 & .05 & -0.9 & .3 \\
\hline 2005 & -0.3 & .006 & -0.5 & .05 & -0.6 & .08 & -0.9 & .2 \\
\hline 2006 & -0.2 & .08 & -0.5 & .08 & -0.5 & .2 & -0.6 & .4 \\
\hline 2007 & -0.2 & .2 & -0.4 & .1 & -0.6 & .09 & -0.8 & .3 \\
\hline 2008 & -0.2 & .2 & -0.6 & .05 & -0.6 & .07 & -1 & .2 \\
\hline 2009 & -0.09 & .5 & -0.5 & .08 & -0.5 & .2 & -0.9 & .3 \\
\hline 2010 & 0.05 & .7 & 0.4 & .2 & -0.3 & .3 & -0.8 & .3 \\
\hline 2011 & 0.06 & .6 & -0.1 & .6 & -0.2 & .6 & -0.7 & .4 \\
\hline 2012 & 0.2 & .1 & -0.2 & .5 & -0.2 & .6 & -0.5 & .5 \\
\hline 2013 & 0.1 & .3 & -0.2 & .4 & -0.3 & .4 & -0.5 & .5 \\
\hline Prostaglandin use & -0.08 & .005 & 0.05 & .2 & 0.08 & .2 & 0.05 & .5 \\
\hline RACHS-1 score & 0.1 & $<.001$ & 0.2 & $<.001$ & 0.3 & $<.01$ & 0.4 & $<.001$ \\
\hline Prematurity & 0.1 & .004 & 0.1 & .06 & 0.4 & .002 & 0.3 & .2 \\
\hline Low birth weight & 0.2 & $<.001$ & 0.2 & .03 & -0.07 & .6 & -0.07 & .7 \\
\hline $\begin{array}{l}\text { Other genetic or major } \\
\text { noncardiac defect }\end{array}$ & 0.4 & $<.001$ & 0.4 & $<.001$ & 0.4 & $<.01$ & 0.4 & .001 \\
\hline Heterotaxy syndrome & 0.2 & $<.001$ & 0.09 & .4 & 0.04 & .8 & 0.1 & .7 \\
\hline Center volume & & $<.001$ & & $<.001$ & & $<.001$ & & .03 \\
\hline Lowest tertile, $<50$ cases/y & ref & & ref & & ref & & ref & \\
\hline Middle tertile, $50-75$ cases/y & 0.1 & .2 & 0.03 & .7 & 0.08 & .5 & 0.009 & .9 \\
\hline Highest tertile, $>75$ cases/y & -0.4 & $<.001$ & -0.4 & $<.001$ & -0.4 & .001 & -0.4 & .02 \\
\hline
\end{tabular}

RACHS-1, Risk adjustment for congenital heart surgery. 
TABLE E3. Sensitivity analysis of the generalized estimating equation for the outcome of total hospital cost: using a propensity matching analysis with 1:1 matching between NICU and CICU (NICU referent)

\begin{tabular}{lcc}
\hline \multirow{2}{*}{$\begin{array}{c}\text { Age at admission/ } \\
\text { admission location }\end{array}$} & \multicolumn{2}{c}{ Total hospital cost (propensity score model) } \\
\cline { 2 - 3 } Adjusted difference & $\boldsymbol{P}$ value \\
\hline $0-1 \mathrm{~d}$ & & \\
$\mathrm{CICU}$ & $\$ 5541$ & .3 \\
$\mathrm{PICU}$ & - & - \\
$2-7 \mathrm{~d}$ & $-\$ 17,446$ & .02 \\
$\mathrm{CICU}$ & - & - \\
PICU & & \\
$8-14 \mathrm{~d}$ & $-\$ 42,748$ & $<.01$ \\
$\mathrm{CICU}$ & - & - \\
PICU & & .4 \\
$>15 \mathrm{~d}$ & $-\$ 16,432$ & - \\
$\mathrm{CICU}$ & - & \\
PICU & & \\
\hline
\end{tabular}

$C I C U$, Cardiac intensive care unit; $P I C U$, pediatric intensive care unit.
TABLE E5. Sensitivity analysis of the generalized estimating equation for the outcome of total hospital cost: excluding patients with prematurity adjusted for the prespecified covariates

\begin{tabular}{lcc}
\hline \multirow{2}{*}{$\begin{array}{c}\text { Age at admission/ } \\
\text { admission location }\end{array}$} & \multicolumn{2}{c}{ Total hospital cost (excluding mortality) } \\
\cline { 2 - 3 } & Adjusted difference & $\boldsymbol{P}$ value \\
\hline $0-1 \mathrm{~d}$ & $\$ 1650$ & .8 \\
$\mathrm{CICU}$ & $\$ 12,510$ & .07 \\
PICU & & \\
$2-7 \mathrm{~d}$ & $-\$ 10,490$ & .12 \\
CICU & $-\$ 17,630$ & .02 \\
PICU & & \\
$8-14 \mathrm{~d}$ & $-\$ 20,850$ & .02 \\
CICU & $-\$ 24,440$ & $<.01$ \\
PICU & & .8 \\
$>15 \mathrm{~d}$ & $-\$ 3290$ & .3 \\
CICU & $-\$ 14,140$ & \\
PICU &
\end{tabular}

CICU, Cardiac intensive care unit; $P I C U$, pediatric intensive care unit.

TABLE E4. Sensitivity analysis of the generalized estimating equation for the outcome of total hospital cost: excluding patients with in-hospital mortality adjusted for the prespecified covariates

\begin{tabular}{lcc}
\hline \multirow{2}{*}{$\begin{array}{c}\text { Age at admission/ } \\
\text { admission location }\end{array}$} & \multicolumn{2}{c}{ Total hospital cost (excluding prematurity) } \\
\cline { 2 - 3 } 0 Adjusted difference & $P$ value \\
\hline 0 - d & $\$ 4760$ & .5 \\
CICU & $\$ 16,030$ & .04 \\
PICU & & \\
$2-7 \mathrm{~d}$ & $-\$ 20,300$ & .002 \\
CICU & $-\$ 25,590$ & .01 \\
PICU & & \\
$8-14 \mathrm{~d}$ & $-\$ 14,670$ & .1 \\
CICU & $-\$ 21,560$ & .04 \\
PICU & & .8 \\
$>15 \mathrm{~d}$ & $\$ 3530$ & .3 \\
CICU & $-\$ 14,340$ & \\
PICU & & \\
\hline
\end{tabular}

$\overline{C I C U}$, Cardiac intensive care unit; $P I C U$, pediatric intensive care unit. 